\title{
POLA SERAPAN HARA DAN PERTUMBUHAN BEBERAPA VARIETAS KEDELAI DENGAN BUDIDAYA JENUH AIR DI LAHAN RAWA PASANG SURUT
}

Nutrient Uptake and Growth of Soybean Varieties under Saturated Soil Culture on Tidal Swamps

\author{
Danner Sagala ${ }^{1}$, Munif Ghulamahdi ${ }^{2 *}$, Maya Melati ${ }^{2}$ \\ ${ }^{1}$ Program Studi Agroteknologi, Fakultas Pertanian, Universitas Prof. Dr. Hazairin, S.H. \\ Jl. Jend. Sudirman No. 185 Bengkulu \\ ${ }^{2}$ Departmen Agronomi dan Hortikultura, Fakultas Pertanian, Institut Pertanian Bogor \\ Jl. Meranti Kampus Darmaga, Bogor 16680 \\ *Penulis untuk korespondensi: E-mail: mghulamahdi@yahoo.com
}

\begin{abstract}
Saturated soil culture (SSC) technology appropriate to prevent pyrite oxidation on tidal swamps and has been proved to increase the productivity of soybean on non-tidal swamp. The objective of the research was to determine the growth response of soybean varieties under saturated soil culture on tidal swamps. The research was conducted at Banyu Urip, Tanjung Lago, Banyuasin District, and South Sumatera Province, Indonesia from April to August 2009. The experiment was arranged in a split plot design with three replications. The main-plot of the experiment was water depth in the furrow consisted of 10, 20, 30, and $40 \mathrm{~cm}$ under soil surface (USS). The subplot of the experiments was soybean varieties consisted of Tanggamus, Slamet, Wilis, and Anjasmoro. No-watering was arranged out of the design as a comparison. The result showed that nutrient absorption of N, K and Mn by Tanggamus was higher than those of other varieties, except $\mathrm{K}$, however $\mathrm{K}$ absorption of Tanggamus was not significantly different from Anjasmoro. $\mathrm{P}$ and $\mathrm{Fe}$ absorption of Tangamus tended to be higher than the other varieties, although statistically they were not affected by variety. However, technically and economically, $20 \mathrm{~cm}$ USS was the most appropriate water depth for soybean production at tidal swamps.
\end{abstract}

Key words: $\quad$ Glycine max (L.) Merr., Tanggamus, Slamet, Wilis, Anjasmoro, pyrite

\section{PENDAHULUAN}

Salah satu upaya pengembangan lahan pertanian adalah melalui pemanfaatan lahan potensial. Lahan rawa merupakan salah satu ekosistem yang sangat potensial untuk pengembangan kedelai di masa depan (Sudaryono et al. 2007). Luas lahan rawa pasang surut di Indonesia berkisar 20 juta ha (Subagyo 2006) dan diperkirakan sekitar 9.53 juta ha cocok untuk usaha pertanian (Suyamto et al. 2007). Sumberdaya lahan rawa di Indonesia secara dominan terdapat di empat pulau besar di luar Jawa, yaitu Pulau Sumatera, Kalimantan, Papua, dan sebagian kecil di Pulau Sulawesi (Subagyo 2006). Tahun 2008 Departemen Pertanian merencanakan pencapaian areal tanam kedelai sekitar satu juta hektar meliputi berbagai provinsi di Indonesia. Areal pengembangan kedelai tersebut termasuk juga lahan pasang surut yang ada di Sumatera Selatan (Deptan 2008).

Permasalahan pengembangan kedelai di lahan pasang surut adalah tanaman kedelai tidak tahan dengan air yang berlebihan sebagaimana karakteristik lahan rawa, sedangkan apabila lahan dikeringkan akan mengoksidasi pirit. Pirit dapat menyebabkan rendahnya $\mathrm{pH}$ tanah pada kondisi teroksidasi. Kadar pirit yang tinggi menyebabkan produktivitas kedelai di lahan pasang surut masih rendah, $800 \mathrm{~kg} / \mathrm{ha}$ (Djayusman et al. 2001). Selanjutnya Suastika dan Sutriadi (2001) menyatakan bahwa rendahnya produktivitas tanaman di lahan pasang surut disebabkan oleh kemasaman tanah yang tinggi sehingga kelarutan $\mathrm{Fe}, \mathrm{Al}$, dan $\mathrm{Mn}$ menjadi tinggi, 
serta rendahnya ketersediaan P dan K. Oleh sebab itu dalam memanfaatkan lahan rawa secara berkelanjutan, diperlukan teknologi pengelolaan lahan yang tepat dan terpadu.

Budidaya jenuh air adalah sistem produksi yang dikembangkan di daerah semi arid tropis Australia yang dilaporkan dapat meningkatkan hasil kedelai di atas pencapaian yang ditanam dengan irigasi konvensional (Fehr et al. 1971; Garside et al. 1982; Nathanson et al. 1984; Troedson et al. 1984; Lawn 1985). Teknologi budidaya jenuh air mempertahankan air dalam saluran antara bedengan dari awal stadia vegetatif hingga stadia kematangan (Ghulamahdi, 1999). Teknologi ini memberi peluang untuk menekan oksidasi pirit sehingga kedelai dapat dibudidayakan di lahan pasang surut. Usaha penurunan kadar pirit dapat dilakukan dengan cara pengaturan kedalaman muka air agar kondisi tanah lebih reduktif. Kedalaman muka air yang tetap di dalam saluran akan menghilangkan pengaruh dari kelebihan air pada pertumbuhan tanaman.

Kedelai merupakan tanaman lahan kering sehingga menurut CSIRO (1983) dan Ghulamahdi et al. (1991), tanggap varietas kedelai terhadap keadaan jenuh air akan berbeda-beda. Sebagai contoh, varietas kedelai yang berumur panjang biasanya mempunyai pertumbuhan lebih baik dan produksi lebih tinggi dari pada kedelai yang berumur pendek jika dibudidayakan dengan budidaya jenuh air. Selain itu, upaya untuk mengatasi kondisi tanah sulfat masam dapat ditempuh melalui perakitan varietas kedelai yang toleran tanah sulfat masam atau mengadaptasikan varietas-varietas unggul yang sudah ada pada kondisi tanah sulfat masam. Alihamsyah dan Ar-Riza (2006) menemukan bahwa varietas Tanggamus, Wilis, dan Slamet merupakan varietas yang dapat dikembangkan di lahan rawa lebak.

Uraian di atas dan masih sedikitnya informasi mengenai penerapan budidaya jenuh air di lahan rawa pasang surut menunjukkan perlunya mempelajari pengaruh berbagai kedalaman muka air parit dan beberapa varietas yang adaptif dibudidayakan dengan teknologi budidaya jenuh air di lahan pasang surut.

\section{BAHAN DAN METODE}

Penelitian ini dilaksanakan di lahan pasang surut Desa Banyuurip Kecamatan Tanjung Lago Kabupaten Banyuasin Provinsi Sumatera Selatan. Waktu pelaksanaan penelitian mulai bulan April hingga September 2009. Percobaan disusun dalam rancangan petak terpisah (split plot design) dengan rancangan acak kelompok sebagai rancangan lingkungan. Percobaan diulang sebanyak tiga kali. Sebagai petak utama adalah tinggi muka air yang terdiri dari empat taraf, yaitu 10, 20, 30 dan $40 \mathrm{~cm}$ di bawah permukaan tanah (dpt). Sebagai anak petak adalah varietas yang terdiri dari empat jenis yaitu Tanggamus, Slamet, Willis, dan Anjasmoro. Anak petak berukuran $2 \mathrm{~m}$ x $5 \mathrm{~m}$. Setiap petak utama dikelilingi saluran air yang berukuran lebar $30 \mathrm{~cm}$ dan dalamnya $50 \mathrm{~cm}$, dan dengan pengaturan ini maka kondisi petakan selalu basah pada saat irigasi diberikan. Air irigasi diberikan mulai saat tanam.

Pada waktu pengolahan tanah diberikan 2 ton kapur/ha, 2,5 ton pupuk kandang/ha, $400 \mathrm{~kg} \mathrm{SP18/ha}$ dan $100 \mathrm{~kg} \mathrm{KCl} / \mathrm{ha}$. Semua pupuk dan kapur diberikan pada saat pengolahan tanah kemudian diinkubasi selama 2 minggu. Pupuk $\mathrm{N}$ tidak diberikan dengan harapan bintil akar dapat memenuhi kebutuhan tanaman akan nitrogen, namun, untuk membantu pemulihan daun saat aklimatisasi, tanaman disemprot $\mathrm{N}$ melalui daun pada umur 2 dan 4 minggu dengan konsentrasi 7,5 g urea/l air. Setelah dua minggu masa inkubasi kapur dan pupuk kandang, kedelai yang telah diberi inokulan Rhizobium sp (5 g/kg benih) dan insektisida berbahan aktif karbosulfan 25,53\% (15 g/kg benih) ditanam. Insektisida ini diberikan untuk mengatasi lalat bibit. Benih ditanam dangkal dengan kedalaman 2-3 cm dengan jarak tanam $20 \mathrm{~cm}$ x $25 \mathrm{~cm}$ dimana setiap lubang diisi dengan dua biji benih kedelai sehingga populasi per petak berjumlah 400 tanaman. Pemeliharaan meliputi penjagaan kecukupan air sesuai dengan perlakuan 
tinggi muka air, pengendalian gulma dan pengendalian hama. Gulma dikendalikan dengan cara mekanis, dan hama dikendalikan dengan menggunakan insektisida.

Pengamatan dilakukan pada tanaman mulai pada peubah tinggi tanaman $(\mathrm{cm})$, jumlah daun trifoliate (daun), jumlah cabang (cabang), jumlah polong isi (polong), analisis hara daun pada umur 6 minggu yang meliputi N, P, K, dan analisis fisik dan kimia tanah sebelum penanaman.

\section{HASIL DAN PEMBAHASAN}

Hasil

\section{Agroekologi Lokasi Penelitian}

Lokasi penelitian berjarak $42 \mathrm{~km}$ dari Selat Bangka dengan ketinggian 1-2 m dari permukaan laut. Berdasarkan tipe luapan, areal ini termasuk dalam tipe luapan C (Monografi desa Banyu Urip). Semua saluran belum dilengkapi pintu air, sehingga sistem pengelolaan air hanya tergantung dengan fluktuasi pasang surut air laut. Jaringan drainase terdiri dari saluran primer, sekunder, tersier dan saluran kuarter. Saat volume air sungai relatif tetap atau berkurang di musim kemarau, pengaruh air asin/salin dapat merambat sepanjang sungai sampai jauh ke pedalaman. Pengaruh air asin/salin di sungai dapat mencapai lokasi penelitian pada bulan-bulan terkering yaitu bulan Agustus-Oktober. Oleh karena itu, lahan pasang surut lokasi penelitian termasuk dalam zona II, yaitu pasang surut air tawar, menurut klasifikasi Widjaja-Adhi et al. (1992) dan Subagyo (1997). Curah hujan tertinggi mencapai $560.8 \mathrm{~mm}$ dan terjadi pada bulan Maret 2009, kemudian curah hujan menurun hingga bulan Agustus 2009 yang hanya mencapai $39.6 \mathrm{~mm}$. Suhu udara di lokasi penelitian adalah 27.7$34.4^{\circ} \mathrm{C}$.

Kesuburan tanah relatif baik dengan kandungan bahan organik, $\mathrm{P}_{2} \mathrm{O}_{5}$ dan $\mathrm{K}_{2} \mathrm{O}$ yang tinggi, namun sangat masam. Nilai tukar kation $\mathrm{Ca}$, $\mathrm{K}$ dan Na rendah, namun nilai tukar kation $\mathrm{Mg}$ tergolong tinggi. Kapasitas tukar kation dan kejenuhan basa sedang. Tekstur tanah adalah liat berdebu. Tanah mengandung pirit dan Fe (Tabel 1).
Tabel 1. Data analisis tanah sebelum olah tanah dan sesudah panen

\begin{tabular}{lcc}
\hline $\begin{array}{l}\text { Peubah } \\
\text { analisis }\end{array}$ & $\begin{array}{l}\text { Sebelum olah } \\
\text { tanah }\end{array}$ & Saat panen \\
\hline $\mathrm{pH}$ & 3.8 & 5.37 \\
$\mathrm{P}_{2} \mathrm{O}_{5}$ & & \\
$($ Bray 1$)$ & $21.4 \mathrm{ppm}$ & $194.60 \mathrm{ppm}$ \\
$\mathrm{K}_{2} \mathrm{O}$ & & \\
(Morgan) & $117 \mathrm{ppm}$ & $50.68 \mathrm{ppm}$ \\
$\mathrm{Fe}$ & $1.19 \%$ & $1.13 \%$ \\
Pirit & $0.47 \%$ & $0.17 \%$ \\
\hline
\end{tabular}

Tabel 2 Data analisis air

\begin{tabular}{|c|c|c|}
\hline No & $\begin{array}{l}\text { Peubah } \\
\text { analisis }\end{array}$ & Hasil analisis \\
\hline 1 & DHL $25^{\circ} \mathrm{C}$ & $0.493 \mathrm{dS} / \mathrm{m}$ \\
\hline 2 & pH & 4.6 \\
\hline \multirow[t]{11}{*}{3} & Kation & (me/l air bebas lumpur) \\
\hline & a. $\underline{N H}_{4}$ & a. $\underline{0.02}$ \\
\hline & b. $\underline{\mathrm{K}}$ & b. $\underline{0.09}$ \\
\hline & c. $\underline{\mathrm{Ca}}$ & C. $\underline{0.40}$ \\
\hline & d. $\mathrm{Mg}$ & d. 1.17 \\
\hline & e. $\underline{\mathrm{Na}}$ & e. 3.42 \\
\hline & f. $\mathrm{Fe}$ & f. $\quad 0.00$ \\
\hline & g. $\underline{\mathrm{Al}}$ & g. $\underline{0.05}$ \\
\hline & h. $\mathrm{Mn}$ & h. 0.01 \\
\hline & i. Jumlah & i. $\underline{5.16}$ \\
\hline & $\underline{\text { kation }}$ & \\
\hline \multirow[t]{8}{*}{4} & Anion & (me/l air bebas lumpur) \\
\hline & a. $\underline{\mathrm{NO}}_{3}$ & a. $\underline{0.01}$ \\
\hline & b. $\underline{P O}_{4}^{-}$ & b. $\overline{0.00}$ \\
\hline & c. $\underline{\mathrm{SO}}_{4}$ & c. $\underline{1.67}$ \\
\hline & d. $\underline{\mathrm{Cl}}$ & d. 3.27 \\
\hline & e. $\underline{\mathrm{HCO}}_{3}$ & e. $\underline{0.03}$ \\
\hline & f. $\underline{\mathrm{CO}}_{3}$ & f. $\underline{0.00}$ \\
\hline & g. $\frac{\text { Jumlah }}{\text { anion }}$ & g. $\underline{4.98}$ \\
\hline 5 & $\begin{array}{l}\text { Kadar } \\
\text { lumpur }\end{array}$ & $50 \mathrm{mg} / \mathrm{l}$ \\
\hline
\end{tabular}

Kandungan kation dan anion dalam air didominasi oleh $\mathrm{Na}$ dan $\mathrm{Cl}$, namun daya hantar listrik air tidak terlalu tinggi yaitu $0.493 \mathrm{dS} / \mathrm{m}$. Air ini juga memiliki keasaman yang tinggi dengan $\mathrm{pH} 4.6$ (Tabel 2).

\section{Serapan Hara dan Pertumbuhan}

Pertumbuhan kedelai yang ditanam dengan teknologi BJA nyata lebih baik 
dibandingkan kedelai yang ditanam tanpa BJA (pembanding). Tanaman pembanding hanya menghasilkan rerata tinggi tanaman 36.75 cm, 17.3 daun, dan 2.5 cabang. Namun tidak terdapat perbedaan yang nyata pada pertumbuhan dan serapan hara tanaman antar kedalaman muka air 10, 20, 30 dan $40 \mathrm{~cm}$ DPT pada BJA.

Varietas Anjasmoro umur 4 dan 6 MST nyata paling tinggi dengan jumlah daun yang berbeda tidak nyata dengan varietas Tanggamus. Jumlah daun varietas Tanggamus lebih banyak namun tidak berbeda nyata dengan varietas Slamet dan Anjasmoro. Jumlah daun varietas Wilis nyata terendah dibanding varietas lainnya. Semua varietas belum mengeluarkan cabang hingga umur 6 MST (Tabel 3).

Tabel 3 Pengaruh varietas terhadap komponen pertumbuhan kedelai pada BJA

\begin{tabular}{lccccc}
\hline \multirow{2}{*}{ Varietas } & \multicolumn{5}{c}{ Umur Tanaman (MST) } \\
\cline { 2 - 6 } & 4 & 6 & 8 & 10 & 13 \\
\hline Tinggi tanaman & & & & & \\
Tanggamus & $21.37 \mathrm{c}$ & $41.90 \mathrm{c}$ & $61.73 \mathrm{~b}$ & $63.32 \mathrm{~b}$ & $64.44 \mathrm{~b}$ \\
Slamet & $24.12 \mathrm{~b}$ & $48.91 \mathrm{~b}$ & $80.22 \mathrm{a}$ & $83.14 \mathrm{a}$ & $85.09 \mathrm{a}$ \\
Wilis & $23.95 \mathrm{~b}$ & $48.80 \mathrm{~b}$ & $60.12 \mathrm{~b}$ & $62.20 \mathrm{~b}$ & $63.40 \mathrm{~b}$ \\
Anjasmoro & $27.50 \mathrm{a}$ & $54.30 \mathrm{a}$ & $59.03 \mathrm{~b}$ & $60.20 \mathrm{~b}$ & $61.02 \mathrm{~b}$ \\
\hline Jumlah daun & & & & & \\
Tanggamus & $6.1 \mathrm{a}$ & $18.2 \mathrm{a}$ & $28.9 \mathrm{a}$ & & \\
Slamet & $6.0 \mathrm{a}$ & $14.5 \mathrm{bc}$ & $24.1 \mathrm{~b}$ & & \\
Wilis & $5.4 \mathrm{~b}$ & $13.4 \mathrm{c}$ & $19.2 \mathrm{c}$ & & \\
Anjasmoro & $5.9 \mathrm{a}$ & $15.0 \mathrm{~b}$ & $18.0 \mathrm{c}$ & & \\
\hline Jumlah cabang & & & & & \\
Tanggamus & & & $2.7 \mathrm{a}$ & $4.4 \mathrm{a}$ & $6.4 \mathrm{a}$ \\
Slamet & & \multicolumn{5}{c}{$3.1 \mathrm{~b}$} & $5.3 \mathrm{~b}$ \\
Wilis & & $2.6 \mathrm{bc}$ & $2.8 \mathrm{c}$ & $3.8 \mathrm{c}$ \\
Anjasmoro & & & $2.3 \mathrm{c}$ & $2.4 \mathrm{c}$ & $3.4 \mathrm{c}$
\end{tabular}

Ket: angka yang diikuti dengan huruf yang sama pada kolom yang sama menyatakan berbeda tidak nyata pada taraf 5\% dengan uji DMRT

Pola pertumbuhan tanaman pada umur 8 dan 10 MST berbeda dengan pola pertumbuhan sebelumnya. Semua varietas telah membentuk percabangan dan tanaman tertinggi diperoleh pada varietas Slamet. Jumlah daun dan cabang varietas Tanggamus tetap nyata lebih banyak dibandingkan varietas lainnya.

Puncak pertumbuhan tanaman adalah pada umur 8 MST. Pertambahan tinggi tanaman dari umur 4-6 MST mencapai 100\% dari tinggi 4 MST, dari umur 6-8 MST mencapai 35\% dari tinggi 6 MST, sedangkan dari umur 8-10 MST hanya bertambah 1-3\%. Pertambahan jumlah daun yang dihitung pada penelitian ini hanya sampai umur 8 MST karena pada umur 10 MST daun sudah mulai gugur. Pertambahan daun dari umur 46 MST adalah 10 daun, sementara dari umur 6-8 MST adalah 7 daun.

Bobot kering semua komponen tanaman varietas Tanggamus nyata lebih tinggi dibandingkan dengan varietas lainnya, kecuali bobot kering bintil akar. Bobot kering bintil akar varietas Anjasmoro merupakan yang tertinggi, akan tetapi berbeda tidak nyata dengan varietas Tanggamus. Bobot kering total varietas Wilis merupakan yang terendah, akan tetapi berbeda tidak nyata dengan varietas Slamet dan Anjasmoro. Bobot kering semua komponen pertumbuhan dan bobot total tinggi pada kedalaman muka air $20 \mathrm{~cm}$ DPT meskipun secara statistik berbeda tidak nyata 
dengan kedalaman muka air lainnya. Bobot kering yang tinggi menyebabkan serapan hara varietas Tanggamus dan kedalaman muka air $20 \mathrm{~cm}$ DPT nyata lebih tinggi yang lainnya (Tabel 4 \& 5).

Tabel 4 Bobot kering batang, daun, akar, bintil akar dan total beberapa varietas kedelai dan kedalaman muka air pada BJA

\begin{tabular}{lccccc}
\hline \multirow{2}{*}{ Perlakuan } & \multicolumn{5}{c}{ Bobot kering (g) } \\
\cline { 2 - 6 } & Batang & Daun & Akar & Bintil akar & Total \\
\hline Varietas & & & & & \\
Tanggamus & 31.03 & $32.80 \mathrm{a}$ & $7.31 \mathrm{a}$ & $1.79 \mathrm{ab}$ & $72.93 \mathrm{a}$ \\
Slamet & 27.79 & $23.97 \mathrm{~b}$ & $6.14 \mathrm{ab}$ & $1.41 \mathrm{~b}$ & $59.32 \mathrm{~b}$ \\
Wilis & 25.57 & $22.03 \mathrm{~b}$ & $5.49 \mathrm{~b}$ & $1.67 \mathrm{~b}$ & $54.75 \mathrm{~b}$ \\
Anjasmoro & 27.52 & $26.45 \mathrm{~b}$ & $5.46 \mathrm{~b}$ & $2.41 \mathrm{a}$ & $61.84 \mathrm{ab}$ \\
\hline \multicolumn{1}{l}{ Kedalaman } & muka air & & & & \\
$10 \mathrm{~cm}$ & 27.91 & 25.15 & 6.44 & 1.97 & 61.47 \\
$20 \mathrm{~cm}$ & 31.52 & 28.97 & 6.50 & 1.89 & 68.88 \\
$30 \mathrm{~cm}$ & 27.44 & 25.90 & 5.54 & 1.72 & 60.60 \\
$40 \mathrm{~cm}$ & 25.03 & 25.24 & 5.93 & 1.70 & 57.90 \\
\hline
\end{tabular}

Ket: angka yang diikuti dengan huruf yang sama pada kolom yang sama menyatakan berbeda tidak nyata pada taraf 5\% dengan uji DMRT

Tabel 5 Kadar dan serapan hara N, P, K, Fe dan Mn dalam daun pada beberapa varietas kedelai dan kedalaman muka air pada BJA

\begin{tabular}{|c|c|c|c|c|c|}
\hline Perlakuan & $\mathrm{N}$ & $\mathrm{P}$ & $\mathrm{K}$ & $\mathrm{Fe}$ & Mn \\
\hline \multicolumn{6}{|l|}{ Varietas } \\
\hline \multicolumn{6}{|c|}{ Kadar hara daun (\%) } \\
\hline Tanggamus & 3.36 a & 0.31 & 1.39 & 0.03 & 0.02 \\
\hline Slamet & $3.36 \mathrm{a}$ & 0.33 & 1.28 & 0.03 & 0.01 \\
\hline Wilis & $2.91 \mathrm{~b}$ & 0.37 & 1.28 & 0.04 & 0.02 \\
\hline Anjasmoro & $3.19 a b$ & 0.36 & 1.56 & 0.04 & 0.01 \\
\hline \multicolumn{6}{|c|}{ Serapan hara daun (mg/tanaman) } \\
\hline Tanggamus & 1100.83 a & 103.33 & $455.83 \mathrm{a}$ & 11.41 & $5.43 \mathrm{a}$ \\
\hline Slamet & 810.00 bc & 78.33 & $311.67 \mathrm{~b}$ & 6.69 & $3.46 \mathrm{~b}$ \\
\hline Wilis & $645.00 \mathrm{c}$ & 79.17 & $288.33 \mathrm{~b}$ & 9.52 & $3.81 \mathrm{~b}$ \\
\hline Anjasmoro & $856.67 \mathrm{~b}$ & 94.17 & $421.67 \mathrm{a}$ & 10.48 & $3.87 \mathrm{~b}$ \\
\hline \multicolumn{6}{|c|}{ Kedalaman muka air } \\
\hline \multicolumn{6}{|c|}{ Kadar hara (\%) } \\
\hline $10 \mathrm{~cm}$ & 3.10 & 0.33 & 1.43 & 0.04 & 0.02 \\
\hline $20 \mathrm{~cm}$ & 3.25 & 0.36 & 1.45 & 0.04 & 0.02 \\
\hline $30 \mathrm{~cm}$ & 3.30 & 0.34 & 1.39 & 0.03 & 0.02 \\
\hline $40 \mathrm{~cm}$ & 3.18 & 0.33 & 1.24 & 0.03 & 0.01 \\
\hline \multicolumn{6}{|c|}{ Serapan hara (mg/tanaman) } \\
\hline $10 \mathrm{~cm}$ & 792.41 & 82.06 & 368.27 & 11.65 & 3.95 \\
\hline $20 \mathrm{~cm}$ & 951.68 & 103.90 & 431.98 & 10.11 & 4.72 \\
\hline $30 \mathrm{~cm}$ & 856.26 & 88.40 & 360.51 & 8.39 & 4.21 \\
\hline $40 \mathrm{~cm}$ & 811.56 & 82.58 & 315.90 & 7.96 & 3.69 \\
\hline
\end{tabular}


Jumlah polong kedelai yang ditanam dengan BJA nyata lebih banyak dibandingkan dengan yang ditanam dengan tanpa pengairan (Tabel 7). Kedelai yang ditanam dengan kedalaman muka air $10 \mathrm{~cm}$ DPT menghasilkan polong 8 kali lebih banyak dibandingkan tanpa pengairan. Varietas Tanggamus, Slamet, Wilis, dan Anjasmoro yang diuji di lahan pasang surut ini pada kedalaman muka air $20 \mathrm{~cm}$ DPT dapat menghasilkan secara berturut-turut 105.4, 96.4, 39.9 dan 42.1 polong/tanaman

Tabel 6 Jumlah polong empat varietas kedelai pada berbagai kedalaman muka air

\begin{tabular}{|c|c|c|c|c|c|}
\hline \multirow{2}{*}{$\begin{array}{c}\text { Kedalaman muka } \\
\text { air }\end{array}$} & \multicolumn{4}{|c|}{ Varietas } & \multirow{2}{*}{ Rerata } \\
\hline & Tanggamus & Slamet & Wilis & Anjasmoro & \\
\hline $\begin{array}{c}\text { Tanpa } \\
\text { pengairan* }\end{array}$ & 20.6 & 4.8 & 6.6 & 1.3 & 8.3 \\
\hline $10 \mathrm{~cm}$ & 94.1 & 68.2 & 46.9 & 46.1 & $63.8 \mathrm{a}$ \\
\hline $20 \mathrm{~cm}$ & 105.4 & 96.4 & 39.9 & 42.7 & $70.9 \mathrm{a}$ \\
\hline $30 \mathrm{~cm}$ & 107.7 & 75.1 & 47.2 & 38.6 & $67.2 \mathrm{a}$ \\
\hline $40 \mathrm{~cm}$ & 94.5 & 72.5 & 32.3 & 30.9 & $57.6 \mathrm{a}$ \\
\hline Rerata & $100.4 \mathrm{a}$ & $78.0 \mathrm{~b}$ & $41.5 \mathrm{c}$ & $39.4 \mathrm{c}$ & \\
\hline
\end{tabular}

Ket: angka yang diikuti dengan huruf yang sama pada kolom dan baris yang sama menyatakan berbeda tidak nyata pada taraf 5\% dengan uji DMRT

* tanaman pembanding dan tidak masuk dalam rancangan percobaan

\section{Pembahasan}

Pertumbuhan kedelai yang tinggi dengan BJA di lahan pasang surut dibandingkan tanpa pengairan disebabkan oleh adanya air yang stabil di bawah permukaan tanah sehingga lengas tanah dalam keadaan kapasitas lapang dan menekan oksidasi pirit. Data analisis tanah yang dilakukan sebelum pengolahan tanah adalah $\mathrm{pH}(\mathrm{KCl})$ 4.4, $3.15 \mathrm{me} / 100 \mathrm{~g} \mathrm{Al}^{3+}$, $64.5 \mathrm{ppm} \mathrm{Mn,} 1.19 \% \mathrm{Fe}, 0.44 \%$ pirit. Adanya lapisan pirit menjadi penghambat pertumbuhan kedelai jika ditanam saat musim kering tanpa BJA. Hal ini terbukti dari pertumbuhan kedelai tanpa pengairan lebih rendah dibandingkan kedelai dengan BJA. Air tanah pada musim kering akan turun melebihi lapisan pirit. Suriadikarta (2005) menyatakan bahwa pirit yang mengalami oksidasi menghasilkan asam sulfat dan senyawa besi bebas bervalensi 3 $\left(\mathrm{Fe}^{3+}\right)$. Hasil akhirnya merupakan tanah dengan reaksi masam ekstrim $(\mathrm{pH}<3.5)$, dan banyak mengandung ion-ion sulfat $\left(\mathrm{SO}_{4}{ }^{-}\right)$, besi bervalensi $2\left(\mathrm{Fe}^{2+}\right)$, dan aluminium $\left(\mathrm{Al}^{3+}\right)$. Asam sulfat akan melarutkan sejumlah besar logam-logam berat, antara lain $\mathrm{Al}, \mathrm{Mn}, \mathrm{Zn}$ dan $\mathrm{Cu}$ sehingga bersifat toksik. Penerapan BJA akan menyebabkan pirit dalam keadaan reduktif karena sebagian ruang pori tanah diisi oleh air. Oksidasi pirit menjadi Fe dapat ditekan dan terhindar dari penurunan $\mathrm{pH}$ yang makin rendah. Pemberian kapur dan pupuk dapat mengatasi kekurangan unsur hara dan meningkatkan pH tanah yang rendah. Kadar pirit saat panen adalah $0.17 \%$ dan kadar Fe adalah $1.13 \%$ dengan $\mathrm{pH}$ tanah 5.3.

Hasil penelitian Fehr et al. (1971); Ralph (1983); Nathanson et al. (1984) menyimpulkan bahwa pertumbuhan dan hasil yang tinggi pada BJA terjadi karena mendapatkan lengas dalam jumlah cukup sepanjang hidupnya, pertumbuhan bintil terus berlanjut sampai fase pengisian polong dan mengalami penundaan penuaan. Selanjutnya Garside et al. (1982); Troedson et al. (1984) menyatakan bahwa kondisi ini menyebabkan suplai asimilat dari source ke sink berlangsung lama. Menurut Sudaryono et al. (2007), kecukupan penyediaan air untuk mencapai kelengasan tanah optimal 
merupakan komponen budidaya kedelai yang sangat penting.

Salinitas belum mempengaruhi pertumbuhan kedelai karena penelitian dilakukan pada musim kemarau I yaitu bulan April-Agustus 2009. Pada bulan ini air yang berada dalam saluran masih merupakan sisa air hujan, namun kadar kation dan anion air telah dipengaruhi air laut. Kation dan anion yang dominan pada air di lahan pasang surut adalah $\mathrm{Na}$ dan $\mathrm{Cl}$. Salinitas air sangat rendah yaitu daya hantar listrik $0.493 \mathrm{dS} / \mathrm{m}$ (Tabel 2). Menurut Sunarto (2001), daya hantar listrik 2-4 mmhos/cm masih tergolong salinitas rendah dan kedelai mulai berkurang hasilnya pada tekanan osmose $7 \mathrm{dS} / \mathrm{m}$. Oleh sebab itu perlu pengujian penerapan BJA pada musim kemarau II yaitu bulan AgustusNopember.

Pertumbuhan tanaman menunjukkan respon yang berbeda-beda antar varietas yang diuji terhadap BJA di lahan pasang surut. Menurut Ghulamahdi et al. (2006), pertumbuhan kedelai mengalami tekanan pada awal pemberian jenuh air. Akar dan bintil akar menjadi mati dan selanjutnya tumbuh di atas muka air. Pertumbuhan meningkat setelah melewati masa aklimatisasi. Pertumbuhan varietas Tanggamus lebih stabil sejak awal pertumbuhan hingga umur 13 MST yang ditunjukkan oleh peubah tinggi tanaman, jumlah daun dan jumlah cabang (Tabel 3). Pertumbuhan semua varietas mulai berhenti pada umur 8 MST. Pada saat umur 8 MST tanaman telah berada pada fase generatif. Hal ini sesuai dengan tipe pertumbuhan keempat varietas tersebut yang tergolong dalam tipe determinit (Puslitbangtan, 2009).

Kadar hara daun yang dibutuhkan kedelai untuk pertumbuhan optimal adalah 2-5\% N, 0.3-0.5\% P, 1.7-2.5\% K, 50-500 ppm Fe dan 21-100 ppm Mn (Marschner 1995; Small dan Ohlrogge 1973). Rendahnya kadar hara K (1.28-1.56\%) dan tingginya kadar hara Mn (142.58-169.50 ppm) melampaui kadar kecukupan bagi tanaman ternyata belum mempengaruhi pertumbuhan dan produksi kedelai di lahan rawa pasang surut dengan teknologi BJA. Adanya hara N yang memberi pengaruh nyata diduga mampu mendorong pertumbuhan tanaman. Marschner (1995) menyatakan bahwa nitrogen merupakan unsur hara pembentuk sebagian besar komponen tanaman seperti asam amino, sistem enzim dan bagian dari molekul klorofil. Selanjutnya Taiz dan Zeiger (1998) menyatakan bahwa legum dengan bintil akar dapat memanfaatkan gas nitrogen dari udara maupun nitrogen anorganik dari dalam tanah dalam bentuk ion amonium dan nitrat. Nitrat mula-mula direduksi menjadi nitrit oleh nitrat reduktase sedangkan gas nitrogen disemat oleh nitrogenase. Pertumbuhan dan hasil kedelai dengan BJA meningkat karena penyematan nitrogen dan pertumbuhan akar di atas muka air tanah ditingkatkan.

Pola serapan hara daun tanaman kedelai yang dibudidayakan di lahan rawa pasang surut dengan BJA berbeda berbeda dengan penelitian Ghulamahdi (1999) di lahan non-pasang surut, dimana serapan hara meningkat dengan meningkatnya kadar hara daun dan bobot kering daun. Serapan hara N, $\mathrm{P}, \mathrm{K}, \mathrm{Fe}$ dan $\mathrm{Mn}$ varietas Tanggamus secara umum lebih tinggi meskipun kadar hara varietas Tanggamus relatif sama dengan varietas lainnya namun bobot kering varietas Tanggamus nyata lebih tinggi. Perbedaan pola serapan hara antar varietas ini diduga merupakan adaptasi genotipe kedelai terhadap lingkungan rawa pasang surut dimana varietas Tanggamus memperlihatkan adaptasi yang lebih baik.

Varietas Tanggamus menyerap $\mathrm{N}$ lebih banyak dan mampu menggunakan $\mathrm{N}$ secara efisien untuk meningkatkan Bobot kering tanaman. Kadar hara $\mathrm{N}$ pada daun varietas Tanggamus secara statistik sama dengan varietas Slamet, namun bobot kering total varietas Tanggamus nyata lebih besar dibandingkan dengan varietas Slamet. Varietas Slamet lebih banyak menggunakan hara untuk pembentukan akar dan pemanjangan batang, sementara Varietas Tanggamus menggunakannya untuk semua komponen tanaman secara merata (Tabel 3).

Berdasarkan jumlah polong, varietas Tanggamus dapat beradaptasi dengan baik di 
lahan pasang surut dengan teknologi BJA. Hal ini juga dapat dilihat dari jumlah polong varietas Tanggamus yang dengan perlakuan tanpa pengairan dapat mendekati jumlah polong kedelai yang ditanam di lahan nonpasang surut, yaitu 20.56 polong (Tabel 6). Ghulamahdi et al. (2009) menemukan bahwa dengan teknologi BJA di lahan non-pasang surut (Bogor) kedelai hanya menghasilkan 38 (Tanggamus), 49 (Slamet), 27 (Wilis) dan 18 (Anjasmoro) polong/tanaman pada kedalaman muka air yang sama.

Jumlah daun dan jumlah polong yang banyak menguntungkan bagi produktivitas tanaman. Daun merupakan source utama dan polong atau biji juga merupakan sink utama bagi tanaman kedelai. Marschner (1995) menyatakan bahwa keterbatasan source dan sink dapat menghambat laju pertumbuhan dan hasil suatu tanaman. Source yang lemah (sedikit) akan menyebabkan pengisian sink lambat, sebaliknya apabila source kuat (banyak) namun sink lemah juga akan menyebabkan produksi biji yang rendah. Data analisis hara daun (source) dalam penelitian ini menunjukkan serapan hara Tanggamus lebih tinggi (1100 mg N, $103 \mathrm{mg}$ $\mathrm{P}_{2} \mathrm{O}_{5}$, dan $455 \mathrm{mg} \mathrm{K}_{2} \mathrm{O} /$ tanaman) dibandingkan Slamet (810 mg N, $78 \mathrm{mg}$ $\mathrm{P}_{2} \mathrm{O}_{5}$, dan $311 \mathrm{mg} \mathrm{K} \mathrm{K}_{2} \mathrm{O}$ tanaman), Wilis (645 mg $\mathrm{N}, \quad 79 \mathrm{mg} \mathrm{P}_{2} \mathrm{O}_{5}$, dan $288 \mathrm{mg}$ $\mathrm{K}_{2} \mathrm{O} /$ tanaman), dan Anjasmoro (856 mg N, $94 \mathrm{mg} \mathrm{P}_{2} \mathrm{O}_{5}$, dan $421 \mathrm{mg} \mathrm{K} \mathrm{O}_{2}$ /tanaman).

Hasil ini menunjukkan bahwa varietas Tanggamus merupakan varietas yang paling adaptif di lahan pasang surut baik dengan teknologi BJA maupun tanpa pengairan. Alihamsyah dan Ar-Riza (2006) menyatakan bahwa varietas Tanggamus, Wilis dan Slamet merupakan varietas yang dapat beradaptasi dengan baik di lahan rawa lebak. Namun dalam penelitian ini ditemukan bahwa Tanggamus lebih responsif terhadap teknologi BJA di lahan pasang surut dan diikuti oleh varietas Slamet. Hal ini juga sesuai dengan deskripsi varietas Tanggamus dan Slamet yang dirakit untuk adaptasi lahan masam (Puslitbangtan, 2009).

\section{KESIMPULAN}

Serapan hara N, K dan Mn pada varietas Tanggamus lebih tinggi daripada varietas lainnya kecuali hara $\mathrm{K}$ yang menyebabkan berat kering dan jumlah polong varietas Tanggamus lebih banyak

\section{UCAPAN TERIMA KASIH}

Penghargaan dan terima kasih disampaikan kepada Kementrian Riset dan Teknologi yang telah mendanai penelitian ini melalui Program Insentif Tahun 2009. Ucapan terima kasih juga disampaikan kepada petani dan ketua Gapoktan Desa Banyu Urip Kecamatan Tanjung Lago Kabupaten Banyuasin, Sumatera Selatan yang telah membantu terlaksananya penelitian ini.

\section{DAFTAR PUSTAKA}

Alihamsyah T, Ar-Riza I. 2006. Teknologi pemanfaatan lahan rawa lebak. Di dalam: Suriadikarta DA, Kurnia U, Suwanda MH, Hartatik W, Setyorini D, editor. Karakteristik dan Pengelolaan Lahan Rawa. Ed ke-1. Bogor: Balai Besar Penelitian dan Pengembangan Sumberdaya Lahan Pertanian, Badan Penelitian dan Pengembangan Pertanian, Departemen Pertanian. hlm 181-201.

[CSIRO] Commonwealth Scientific and Industrial Research Organisation. 1983. Soybean response to controlled waterlodging. Di dalam: Lehane R, editor. Rural Research. The Science Communication of CSIRO's Beaureau of Scientific Services. hlm 4-8.

[DEPTAN] Departemen Pertanian. 2008. Rencana aksi percepatan peningkatan produksi kedelai tahun 2008. Pertemuan teknis penanaman kedelai. Jakarta. 17 hlm.

Djayusman M, Suastika IW, Soelaeman Y. 2001. Refleksi pengalaman dalam pengembangan sestem usaha pertanian di lahan pasang surut, Pulau Rimau. $\begin{array}{lrr}\text { Seminar Hasil } & \text { Penelitian } \\ \text { Pengembangan Sistem } & \text { Usaha } \\ \text { Pertanian Lahan } & \text { Pasang } & \text { Surut }\end{array}$ 
Sumatera Selatan. Badan Penelitian dan Pengembangan Pertanian, Pusat Penelitian dan Pengembangan Tanah dan Agroklimat. Bogor, Juni 2001.

Fehr WR, Cavines CE, Burmood DT, Pennington JS. 1971. Stage of development descriptions for soybeans Glycine max (L.) Merill. Crop Sci., 11: 929-931.

Garside AL, Lawn RJ, Byth DE. 1982. Irrigation Management of Soybean (Glycine $\max (\mathrm{L}$.$) Merill) in a Semi-$ arid Tropical Environment. III. Response to Saturated Soil Culture. Aust. J. Agric. Res., 43: 1019-1032.

Ghulamahdi M, Rumawas F, Wiroatmojo J, Koswara J. 1991. Pengaruh pemupukan fosfor dan vari terhadap pertumbuhan dan produksi kedelai pada budidaya jenuh air. Forum pasca Sarjana, 14(1): 25-34.

Ghulamahdi M. 1999. Perubahan fisiologi tanaman kedelai (Glycine max (L.) Merill) pada budidaya tadah hujan dan jenuh air. Disertasi. Bogor. Program Pascasarjana. Institut Pertanian. Bogor.

Ghulamahdi M, Aziz SA, Melati M, Dewi N, Rais SA. 2006. Aktivitas nitrogenase, serapan hara dan pertumbuhan dua varietas kedelai pada kondisi jenuh air dan kering. Bul. Agron., 34(1):32-38.

Ghulamahdi M, Melati M, Murdianto. 2009. Penerapan teknologi budidaya jenuh air dan penyimpanan benih kedelai di lahan pasang surut. Laporan akhir program insentif tahun 2009. Kementrian Negara Riset dan Teknologi.

Inderadewa D, Sastrowinoto S, Notohadiswarno S, Prabowo H. 2004. Metabolisme nitrogen pada tanaman kedelai yang mendapat genangan dalam parit. Ilmu Pertanian, 2: 68-75.

Lawn B. 1985. Saturated Soil Culture Expanding the Adaptation of Soybeans. Food Legumes Newsletter, 3: 2-3.

Marschner H. 1995. Mineral Nutrition of Higher Plants. London. Academic Press. hlm 229-369.
Nathanson K, Lawn R L, De Fabrun PLM, Byth DE. 1984. Growth, nodulation and nitrogen accumulation by soybean in saturated soil culture. Field Crops Res., 8: 73-92.

[PUSLITBANGTAN] Pusat Penelitian dan Pengembangan Tanaman Pangan. 2009. Deskripsi Varietas Unggul Palawija 1918-2009. Bogor. $330 \mathrm{hlm}$.

Ralph W. 1983. Soybean Response to Controlled Waterlodging. Rural Res., 120: 4-8.

Small HG, Ohlrogge AJ. 1973. Plant analysis as an aid in fertilizing soybean and peanuts. Di dalam: Walsh LM, Beaton JD, editor. Soil testing and plant analysis. Edisi Revisi. Madison: Soil Science Society of America. hlm 315-327.

Suastika IW, Sutriadi MT. 2001. Pengaruh Perbaikan Tata Air Mikro terhadap Kualitas Air Tanah dan Hasil Tanaman. Seminar Hasil Penelitian Pengembangan Sistem Usaha Pertanian Lahan Pasang Surut Sumatera Selatan. Badan Penelitin dan Pengembangan Pertanian. Pusat Penelitian dan Pengembangan Tanah dan Agroklimat. Bogor. Juni 2001.

Subagyo H. 1997. Potensi pengembangan dan tata ruang lahan rawa untuk pertanian. h. 17-55. Di dalam: A.S. Karama et al., editor. Prosiding Simposium Nasional dan Kongres VI PERAGI. Makalah Utama. Jakarta, 2527 Juni 1996.

Subagyo H. 2006. Klasifikasi dan Penyebaran Lahan Rawa. Di dalam: Suriadikarta, D.A., U. Kurnia, Mamat H.S., W. Hartatik, D. Setyorini, editor. Karakteristik dan Pengelolaan Lahan Rawa. Ed ke-1. Bogor: Balai Besar Penelitian Dan Pengembangan Sumberdaya Lahan Pertanian, Badan Penelitian Dan Pengembangan Pertanian, Departemen Pertanian. Hlm 1-22.

Sudaryono, Taufiq A, Wijanarko A. 2007. Peluang peningkatan produksi kedelai di Indonesia. Dalam: Sumarno, 
Suyamto, Widjono A, Hermanto dan Kasim H, Editor. Kedelai - Teknik Produksi dan Pengembangan. Bogor: Pusat Penelitian dan Pengembangan Tanaman Pangan. Badan Penelitian dan Pengembangan Pertanian. Departemen Pertanian. hlm 130-167.

Sunarto. 2001. Toleransi kedelai terhadap tanah salin. Bul. Agron., 29(1), 27-30.

Suriadikarta DA. 2005. Pengelolaan Lahan Sulfat Masam untuk Usaha Pertanian. Jurnal Litbang Pertanian, 24(1), 36-45.

Suyamto et al. 2007. Pengelolaan tanaman terpadu padi lahan rawa pasang surut. Badan Penelitian dan Pengembangan Pertanian. Departemen Pertanian. 37 hlm.

Taiz L, Zeiger E. 1998. Plant Physiology. Ed ke-2. Massachucetts: Sinauer Associates Inc. Publ. hlm 259-282.

Troedson RJ, Lawn RJ, Byth DE, Wilson GL. 1984. Nitrogen Fixation by
Soybean in Saturated Soil. Austral. Legume Nodulation Conf. Sidney.

Troedson RJ, Garside AL, Lawn RJ, Byth DE, Wilson GL. 1984. Saturated soil culture-an innovative water management option for soybean in the tropics and subtropics. Di dalam: Shanmugasundaram $\mathrm{S}$ and Sulzberger EW, Editor. Soybean in Tropical and Subtropical Cropping Systems. Proc. of a Symp. Tsukuba. Japan. hlm 171180.

Widjaja-Adhi IPG, Nugroho K, Suriadikarta DA, Karama A.S. 1992. Sumberdaya Lahan Rawa: Potensi, keterbatasan dan pemanfaatan. Didalam: Partohardjono, S. dan M. Syam, editor. Risalah Pertemuan Nasional Pengembangan Pertanian Di lahan Rawa Pasang Surut Dan Lebak. Cisarua 3-4 Maret 1992. Badan Litbang Pertanian. Bogor. 